\title{
Influence of the Grade and Content of Fly Ash on the Strength of Cement Mortar
}

\author{
Hongfei $X u^{1, a}$, Wenting $Q u^{1, b}$ \\ ${ }^{1}$ Civil Engineering and Architecture Institute, Zaozhuang University, ZaoZhuang, Shandong, China \\ axuhongfei2012@163.com, bquwenting216@126.com
}

\begin{abstract}
Keywords: fly ash;cement mortar; flexural strength; compressive strength
Abstract. This study added fly ash in cement mortar to replace some cement,using three grades (GradeI、II、III )and three contents (10\%、20\%、30\%)of fly ash respectively to make nine kinds of cement mortar specimen. Standard curing periods were respectively 3,7,14,28 days of each kind of specimen. The compressive strength and flexural strength of these nine kinds specimen at different ages were tested to be compared with the strength of cement mortar specimen with no fly ash.The results show that both the flexural and compressive strength of GradeIand GradeIIfly ash specimen are similar and higher than the strength of Grade III fly ash specimen. When fly ash content is $10 \%$,early flexural strength of GradeIand GradeIIfly ash specimen increase most and the compressive strength at 28 days are higher than that of specimen with no fly ash. Grade III fly ash specimen show tympanites and send out irritating ammonia smell.
\end{abstract}

\section{Introduction}

Fly ash is the major solid waste from coal-fired power plants.At present, China's annual emissions has reached more than 375 million tons. The toxic chemical in fly ash is very harmful to human and creatures and is one of the important pollution sources of environmental pollution. The emission of $\mathrm{CO}_{2}$ is one ton if one ton of cement clinker is produced.According to sustainable development strategy,the development of ordinary Portland cement and other energy-consumption building production will be restricted. Utilization of industrial residue is drawing more and more attention ${ }^{[1]}$.It is of great significance for the governance of industrial residue and environment protection to use fly ash and other industrial residue as cement mixed material or concrete admixture.

Foreign study of fly ash can be traced back to transformation of large-capacity boiler in power plant after $1920^{[2]}$. Caltech in America researched fly ash systematically after 1933 and extended its use to many fields ${ }^{[3]}$.In Japan,27 fly ash concrete dams had been built from 1953 to 1968.

There have been a lot of studies about utilization of fly ash or silica fume in concrete in domestic. According to research results,silica fume should be the concrete admixture for C80 or above concrete.But silica fume is expensive and its high water absorption causes sharp increase of concrete water demand, which restrict the development of concrete ${ }^{[4-5]}$. The influence of fly ash replacing silica fume as admixture on concrete properties has become a research hotspot due to low price of fly ash.But research on the influence of fly ash on cement mortar is infrequent.

This paper studied the influence of the grade and content of fly ash on the strength of cement mortar.The results can promote rational utilization of industrial residue and provide theoretical support to choose rational grade and content of fly ash in cement mortar.

\section{Test materials and methods}

Test materials.Fly ash:fly ash produced in Zhengzhou city of Henan provience(GradeI、II、III);

Cement:ordinary Portland cement P.O32.5 produced by China United Cement Zaozhuang Co.,Ltd

Aggregate:medium sand with all indicators meeting the requirements of test procedures and no impurities ;silt content is less than 5\%; all particles are clean and angular. 
Mix proportion of cement mortar.The study used local common sand ro replace standard sand in order to improve local representativeness of conclusion.On the basis of iterative adjustment of mixture ratio,through comparing normal consistency, compressive and flexural strength at different ages of standard sand mortar and common sand mortar,it was found that standard sand can be replaced by local common sand when the mixture ratio was 1:2:5. The comparison results were shown in Table.1,Figure.1 and Figure.2.

Table.1 Comparison of normal consistency

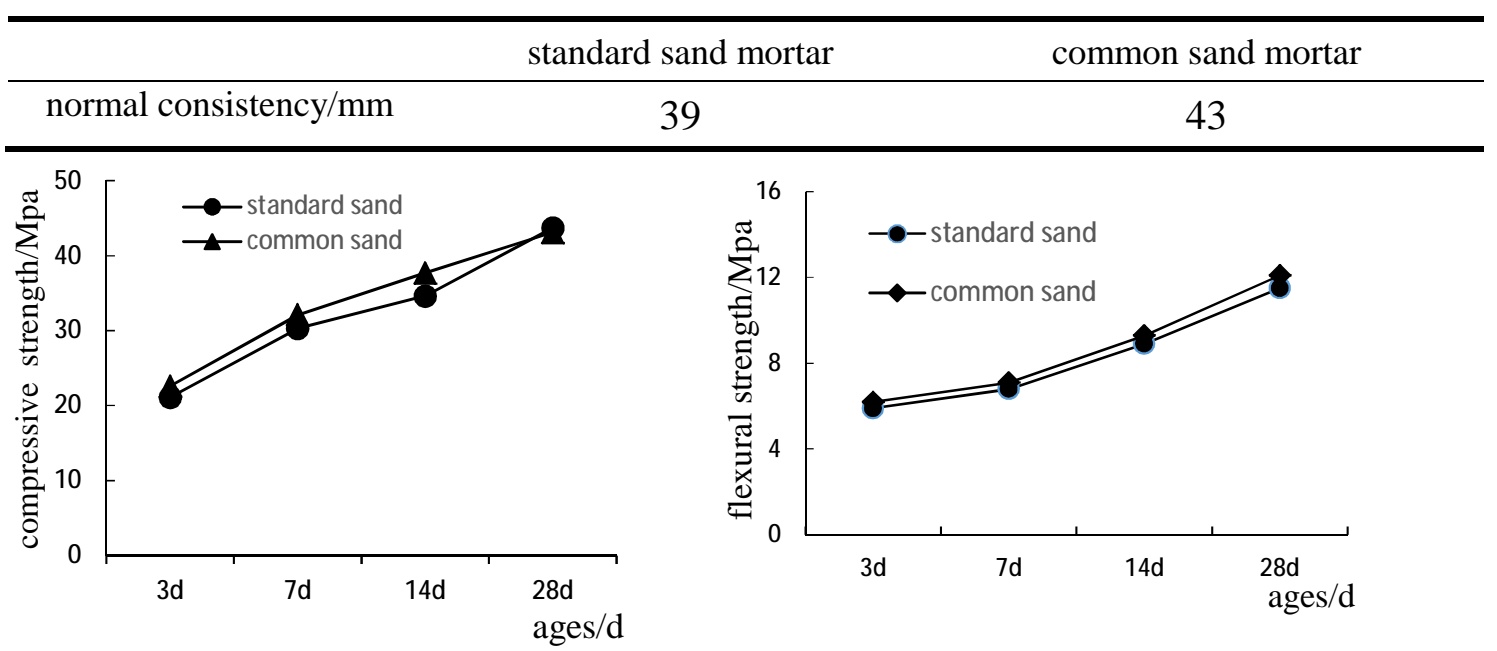

Figure.1 Comparison of compressive strength Figure.2 Comparison of flexural strength

This study added fly ash in cement mortar to replace equal mass of cement,using three grades (GradeI、II、III )and three contents (10\%、20\%、30\%)of fly ash respectively to make nine kinds of cement mortar specimen.

Making and curing of specimen.According to 《Standard for test method of performance on building mortar》(JGJ/T70-2009), the specimen size is $160 \mathrm{~mm} \times 40 \mathrm{~mm} \times 40 \mathrm{~mm}$.Specimens were made in a standard way and numbered,then they would be cured under standard conditions (temp. $20^{\circ} \mathrm{C} \pm 2^{\circ} \mathrm{C}$, relative humidity $\geq 90 \%$ ).

Standard curing periods were respectively 3,7,14,28 days of each kind of specimen.The compressive and flexural strength at different ages of these nine kinds of specimen were tested.

\section{Test results and analysis}

Analysis of flexural strength.According to the test results, variation trends of flexural strength at different ages of specimen made from different grade and content of fly ash were shown in Figs. 1-Figs. 4.

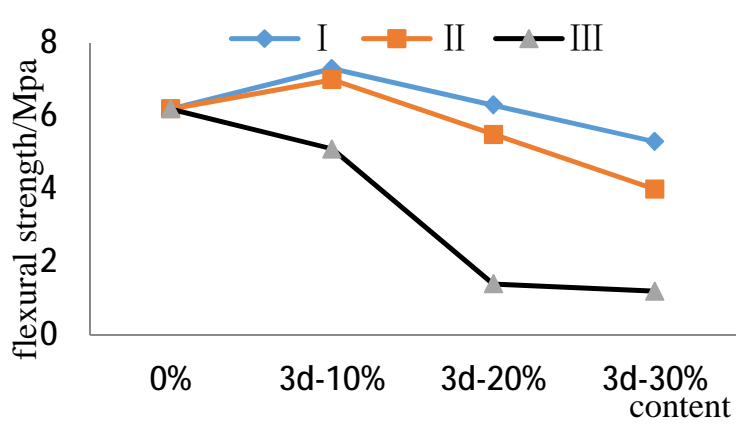

Figure .3 flexural strength at $3 \mathrm{~d}$ age

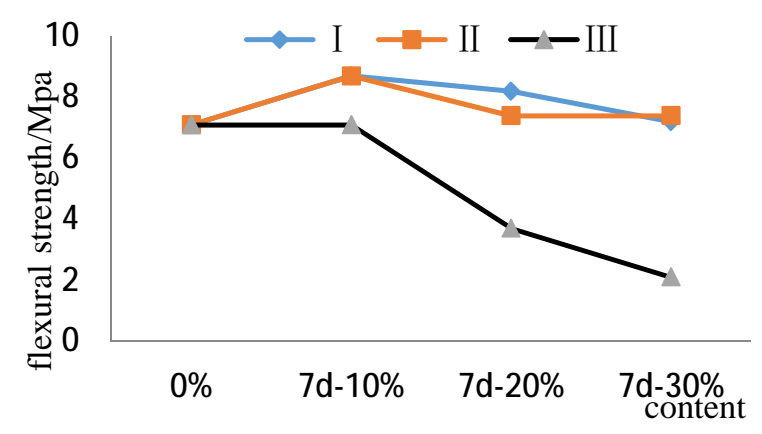

Figure.4 flexural strength at $7 \mathrm{~d}$ age 


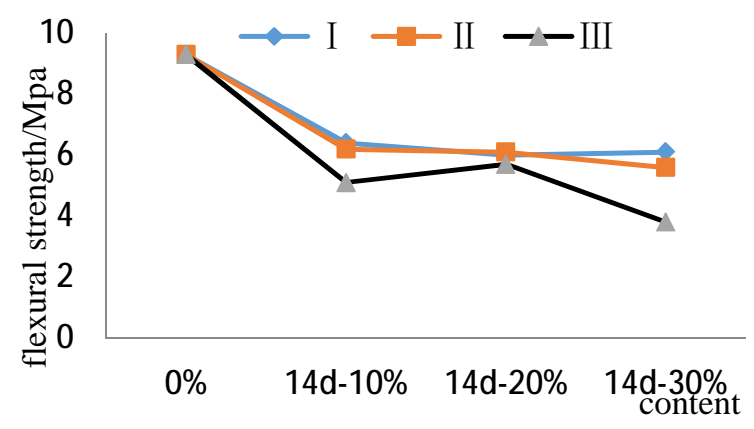

Figure.5 flexural strength at $14 \mathrm{~d}$ age

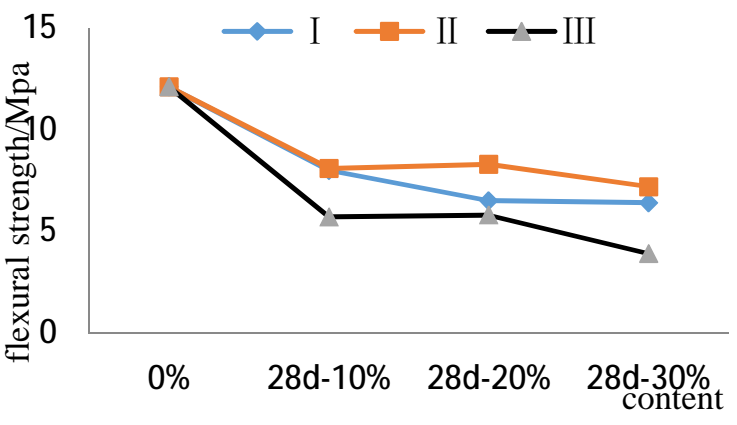

Figure.6 flexural strength at 28d age

The results can be concluded as follows:

(1)Compared with ordinary cement mortar,flexural strength of fly ash specimens decreased on the whole except that early flexural strength of GradeIand GradeIIfly ash specimen increased when fly ash proportion was $10 \%$.

(2) The flexural strength of GradeIand GradeIIfly ash specimen were similar and higher than the strength of Grade III fly ash specimen. When fly ash content was $10 \%$, early flexural strength of GradeIand GradeIIfly ash specimen increased most.

(3)With regard to fly ash specimens of a same grade,flexural strength at every age decreased with the increase of fly ash proportion.

Analysis of compressive strength.According to the test results, variation trends of compressive strength at different ages of specimen made from different grade and content of fly ash were shown in Figs.5-Figs.8.

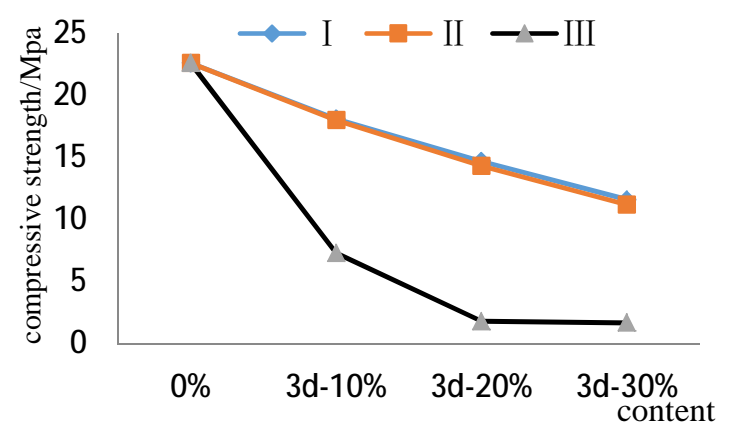

Figure.7 compressive strength at $3 \mathrm{~d}$ age

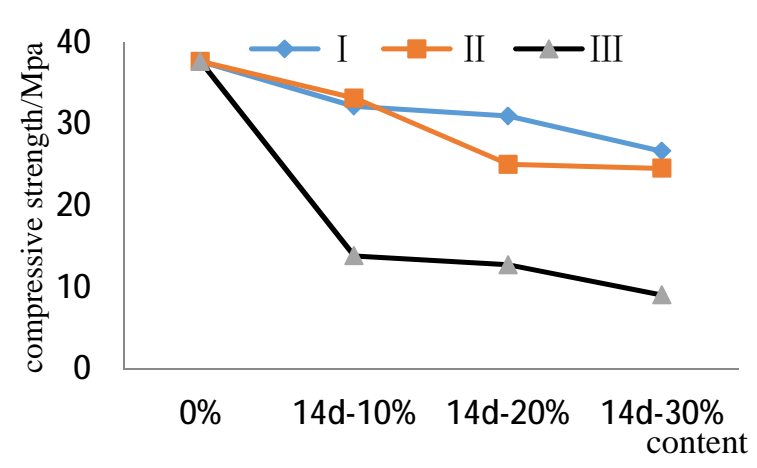

Figure. 9 compressive strength at $14 \mathrm{~d}$ age The results can be concluded as follows:

(1)Compared with ordinary cement mortar,compressive strength of fly ash specimens decreased on the whole,but the extent of reduction decreased with the age.

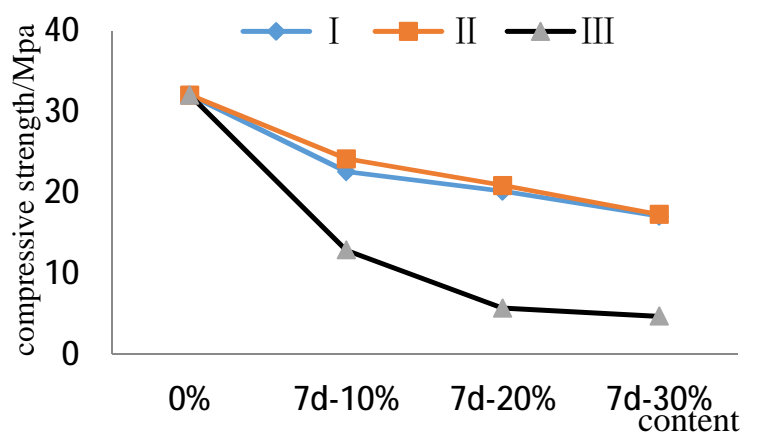

Figure. 8 compressive strength at $7 \mathrm{~d}$ age

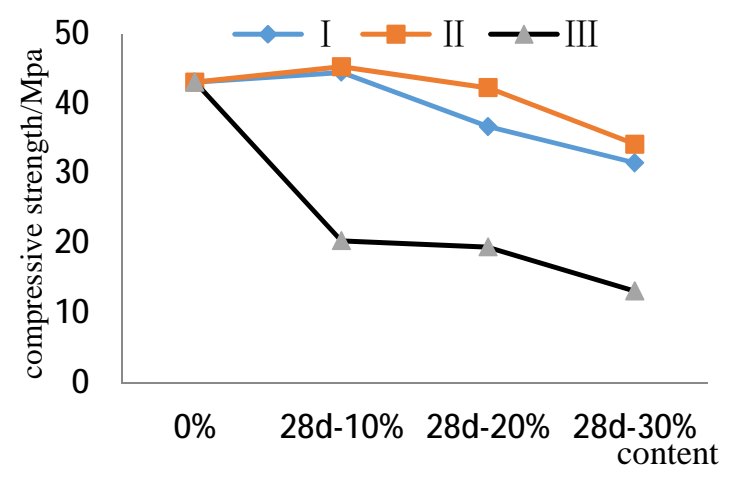

Figure.10 compressive strength at $28 \mathrm{~d}$ age 
(2)The compressive strength of GradeIand GradeIIfly ash specimen were similar and higher than the strength of Grade III fly ash specimen,which is consistent with the results of flexural strength.Compared with ordinary cement mortar,when fly ash content is $10 \%$,early compressive strength of GradeIand GradeIIfly ash specimen decreased but the compressive strength at 28 days increased.

(3)With regard to fly ash specimens of a same grade,compressive strength at every age decreased with the increase of fly ash proportion and this trend was particularly obvious of Grade III fly ash specimen.

Irritating ammonia smell of Grade III fly ash specimen. Grade III fly ash specimen showed tympanites after molding and the phenomena were more obvious when fly ash proportion was $20 \%$ or $30 \%$.Specimens sent out irritating odour after demoulding and the smell was initially identified as ammonia.The reason for tympanites may be that there are anions such as Cl-,CO32-,HCO3-,SO42and NO3- in fly ash after flue gas denitrification and temperature rise due to hydration thermal reaction of cement urges ammonium bicarbonate to release $\mathrm{NH} 3$.

\section{Conclusions}

(1)Compared with ordinary cement mortar,early flexural strength of fly ash specimen increase somewhat while the compressive strength decrease on the whole.

(2)Both the flexural and compressive strength of GradeIand GradeIIfly ash specimens at every age are similar and higher than the strength of Grade III fly ash specimen.The strength at 28d age of GradeIIfly ash specimens are slightly higher than that of GradeIfly ash specimens.

(3)The flexural and compressive strength at every age decrease with the increase of fly ash proportion.But early flexural strength and compressive strength at 28 days of GradeIand GradeIIfly ash specimens increase when fly ash content is $10 \%$.

(4)The reason for ammonia smell of Grade III fly ash specimen should be that ammonia gas produced due to excessive denitration agent is adsorbed by fly ash after denitrification.

\section{References}

[1]Huang Hong,Tang Mingliang,Shen Xiaodong,ZhongBaiqian.The Resourcing of Industrial Waste and Its Sustainable Development(II) - Combine Tightly with Cement and Concrete Industry for Sustainable Development[J].Material guide newspaper,2006,5(20):455-458.

[2]American Coal Ash Association.1996 Coal Combustion Product-Production and Use.Alexandria, Virginia,1997.McKerall,W. C. ,W. B. Ledbetter, and D. J. Teague. Analysis of Fly Ashes Produced in Texas. Texas.2007,14(1):11-12.

[3]Transportation Institute,Texas A\&M University, College Station, Texas, 1982. Reserarch Report No. 240-1.

[4]YANG Hua-quan,QIN Li-li,DONG Wei-jia,WANG Zhong-hua.Study on properties of cement mortar mixed with powdered slag\& flyash[J].Journal of Yangtze River Scientific Research Institute,2001,18(1):16-19.

[5]YU Feng,XIA Yan.Research on the Composite Properties of Ultrafine Fly-ash High-strength Concrete[J].Journal of Wuhan university of technology,2008,30(5):32-34. 